\title{
BIVARIATE MATRIX FUNCTIONS
}

\author{
DANIEL KRESSNER
}

Abstract. A definition of bivariate matrix functions is introduced and some theoretical as well as algorithmic aspects are analyzed. It is shown that our framework naturally extends the usual notion of (univariate) matrix functions and allows to unify existing results on linear matrix equations and derivatives of matrix functions.

Mathematics subject classification (2010): 15A16, 15A24, 15A69.

Keywords and phrases: Matrix functions, multivariate functions, matrix equations.

\section{REFERENCES}

[1] A. C. Ahlin, A bivariate generalization of Hermite's interpolation formula, Math. Comp., 18:264 273, 1964.

[2] R. ARens AND A. P. CAlderón, Analytic functions of several Banach algebra elements, Ann. of Math. (2), 62:204-216, 1955.

[3] B. W. BADER AND T. G. KoldA, Algorithm 862: MATLAB tensor classes for fast algorithm prototyping, ACM Trans. Math. Software, 32(4):635-653, 2006.

[4] R. Bhatia And K. B. Sinha, Derivations, derivatives and chain rules, Linear Algebra Appl., 302/303:231-244, 1999.

[5] H. BILleR, Analyticity and naturality of the multi-variable functional calculus, Expo. Math., 25(2):131-163, 2007.

[6] V. Bolotnikov AND L. Rodman, On positivity of analytic matrix functions in polydisks, Linear Algebra Appl., 328(1-3):69-94, 2001.

[7] JU. L. DALECKIĬ, Differentiation of non-Hermitian matrix functions depending on a parameter, Amer. Math. Soc. Transl., Series 2, 47:73-87, 1965.

[8] JU. L. DALECKII AND S. G. KREĬN, Integration and differentiation of functions of Hermitian operators and applications to the theory of perturbations, Amer. Math. Soc. Transl., Series 2, 47:1-30, 1965.

[9] P. I. DAVIES AND N. J. HighaM, A Schur-Parlett algorithm for computing matrix functions, SIAM J. Matrix Anal. Appl., 25(2):464-485, 2003.

[10] L. De Lathauwer, B. De Moor, and J. Vandewalle, A multilinear singular value decomposition, SIAM J. Matrix Anal. Appl., 21(4):1253-1278, 2000.

[11] T. E. DJAFERIS AND S. K. MitTER, Algebraic methods for the study of some linear matrix equations, Linear Algebra Appl., 44:125-142, 1982.

[12] M. GIL', Norm estimates for functions of two non-commuting matrices, Electron. J. Linear Algebra, 22:504-512, 2011.

[13] L. GRASEDYCK, Existence and computation of low Kronecker-rank approximations for large linear systems of tensor product structure, Computing, 72(3-4):247-265, 2004.

[14] M. GU, Finding well-conditioned similarities to block-diagonalize nonsymmetric matrices is NP-hard, Journal of Complexity, 11(3):377-391, September 1995.

[15] F. Hansen, Operator convex functions of several variables, Publ. Res. Inst. Math. Sci., 33(3):443463, 1997.

[16] N. J. Higham, Accuracy and Stability of Numerical Algorithms, SIAM, Philadelphia, PA, second edition, 2002.

[17] N. J. Higham, Functions of matrices, Society for Industrial and Applied Mathematics (SIAM), Philadelphia, PA, 2008. 
[18] R. A. Horn And C. R. Johnson, Topics in Matrix Analysis, Cambridge University Press, Cambridge, 1991.

[19] E. IsAacson And H. B. Keller, Analysis of numerical methods, Dover Publications Inc., New York, 1994., Corrected reprint of the 1966 original.

[20] I. M. JAIMOUKHA AND E. M. KASENALLY, Krylov subspace methods for solving large Lyapunov equations, SIAM, J. Numer. Anal., 31:227-251, 1994.

[21] I. JONSSON AND B. KÅGSTRÖM, Recursive blocked algorithm for solving triangular systems. I. one-sided and coupled Sylvester-type matrix equations, ACM, Trans. Math. Software, 28(4):392-415, 2002.

[22] B. K̊̊gSTRÖM, Numerical computation of matrix functions, Report UMINF-58.77, Department of Information Processing, University of Umeå, Sweden, July 1977.

[23] A. KorÁnyi, On some classes of analytic functions of several variables, Trans. Amer. Math. Soc., 101:520-554, 1961.

[24] S. G. KRantZ, Function Theory of Several Complex Variables, John Wiley \& Sons Inc., New York, 1982.

[25] M. G. KREǏN, Lektsii po teorii ustoichivosti reshenii differentsialnykh uravnenii v Banakhovom prostranstve, Izdat. Akad. Nauk Ukrain. SSR, Kiev, 1964.

[26] D. KRessner And C. TobleR, Krylov subspace methods for linear systems with tensor product structure, SIAM J. Matrix Anal. Appl., 31(4):1688-1714, 2010.

[27] P. LANCASTER, Explicit solutions of linear matrix equations, SIAM Rev., 12:544-566, 1970.

[28] D. Luminet, Functions of several matrices, Boll. Un. Mat. Ital. B (7), 11(3):563-586, 1997.

[29] M. S. MARINOV, Integral representations of holomorphic functions of one or several matrices, Izv. Vyssh. Uchebn. Zaved. Mat., (6):24-28, 1991.

[30] R. Mathias, Approximation of matrix-valued functions, SIAM J. Matrix Anal. Appl., 14(4):1061$1063,1993$.

[31] R. Mathias, A chain rule for matrix functions and applications, SIAM J. Matrix Anal. Appl., 17(3):610-620, 1996.

[32] I. NAJFeld AND T. F. HAVEL, Derivatives of the matrix exponential and their computation, Advances in Applied Mathematics, 16:321-375, 1995.

[33] C. W. Norman, On the Jordan form of a family of linear mappings, Linear Algebra Appl., 257:225$241,1997$.

[34] G. OpITZ, Steigungsmatrizen, Z. Angew. Math. Mech., 44:T52-T54, 1964.

[35] B. N. PARLETT AND K. C. NG, Development of an accurate algorithm for $\exp (B t)$, Technical Report PAM-294, Center for Pure and Applied Mathematics, University of California, Berkeley, August 1985.

[36] K. Rost, Generalized Lyapunov equations, matrices with displacement structure, and generalized Bezoutians, Linear Algebra Appl., 193:75-93, 1993.

[37] Y. SAAD, Numerical solution of large Lyapunov equations, In Signal processing, scattering and operator theory, and numerical methods (Amsterdam, 1989), volume 5 of Progr. Systems Control Theory, pages 503-511. Birkhäuser Boston, Boston, MA, 1990.

[38] G. E. ŠILOV, On decomposition of a commutative normed ring in a direct sums of ideals, Mat. Sbornik N.S., 32(74):353-364, 1953.

[39] J. Singh Aujla, Matrix convexity of functions of two variables, Linear Algebra Appl., 194:149-160, 1993.

[40] E. STICKEL, On the Fréchet derivative of matrix functions, Linear Algebra Appl., 91:83-88, 1987.

[41] L. WAelbroeck, Le calcul symbolique dans les algèbres commutatives, J. Math. Pures Appl. (9), 33:147-186, 1954.

[42] H. K. WimmeR, Linear matrix equations: the module theoretic approach, Linear Algebra Appl., 120:149-164, 1989.

[43] H. K. Wimmer And A. D. ZIEbur, Solving the matrix equation $\Sigma_{\rho=1}^{r} f_{\rho}(A) X g_{p}(B)=C$, SIAM Rev., 14:318-323, 1972.

[44] H. K. Wimmer And A. D. Ziebur, Blockmatrizen und lineare Matrizengleichungen, Math. Nachr., 59:213-219, 1974. 